\title{
Programme Outcomes Assessment Models in Engineering Faculties
}

\author{
Abdul Wahab Mohammad ${ }^{1} \&$ Azami Zaharim ${ }^{1}$ \\ ${ }^{1}$ Centre for Engineering Education Research, Faculty of Engineering and Built Environment, Universiti \\ Kebangsaan Malaysia, Selangor, Malaysia \\ Correspondence: Abdul Wahab Mohammad, Centre for Engineering Education, Faculty of Engineering and Built \\ Environment, Universiti Kebangsaan Malaysia, 43600 UKM Bangi, Selangor, Malaysia. Tel: 60-3-8921-6410. \\ E-mail:wahabm@eng.ukm.my
}

\author{
Received: September 24, 2012 Accepted: November 7, 2012 Online Published: November 30, 2012 \\ doi:10.5539/ass.v8n16p115 \\ URL: http://dx.doi.org/10.5539/ass.v8n16p115
}

\begin{abstract}
Malaysia is currently a member of Washington Accord which recognises substantial equivalence in the accreditation of qualifications for engineering programme among member countries. Under this agreement, assessment of programme outcomes (PO) is now mandatory for all engineering programmes in Malaysia. However, the typical PO assessment model practised by many engineering programmes resulted in vague assessment methods and as a result failed to show concrete continual quality improvement (CQI). The major issues with the model are with regard to the aspect of unclear performance criteria, grades as measurement indicators, lack of evidence, detached used of indirect methods and unclear CQI. A new model which is more holistic and based on looking at each PO as a major thrust with specific performance criteria is proposed. It is expected that the new model will allow one to objectively evaluate whether the students have achieved the criteria, subsequently facilitating CQI implementation within the programme and produced quality engineering graduates.
\end{abstract}

Keywords: programme outcomes, assessment, assessment model, performance criteria, continuous quality improvement

\section{Introduction}

The introduction of outcome based education (OBE) in the engineering education in Malaysia was started in 2004 when the Board of Engineers Malaysia (BEM) planned for membership in the Washington Accord. OBE has been defined clearly by Spady (1994) as "Outcome-Based Education means clearly focusing and organizing everything in an educational system around what is essential for all students to be able to do successfully at the end of their learning experiences. This means starting with a clear picture of what is important for students to be able to do, then organizing the curriculum, instruction, and assessment to make sure this learning ultimately happens". Killen (2000) described the three basic premises that underpinned OBE in addition to the idea that outcomes should describe long-term significant learning, these are:

1) All students can learn and succeed, but not all in the same time or in the same way.

2) Successful learning promotes even more successful learning.

3) Schools (and teachers) control the conditions that determine whether or not students are successful at school learning.

The programme objectives and outcomes are therefore meant to specifically identify the important aspects of which the programme must be designed. The failure to design the curriculum through outcome based will lead to ambiguous result attainment as succinctly explained by Zitterkopf (1994): "A school that does not specify outcomes simply accepts whatever comes as a result of the educational process and, of course, places little, if any, emphasis on attaining results. Subsequently, quality in the process and product is acquired somewhat arbitrarily".

Thus starting in 2004, the engineering education in Malaysia underwent a major transformation due to the requirement imposed by the Washington Accord agreement. The Washington Accord agreement is an agreement that establishes equivalence of other countries' accredited professional engineering programs. Under the outcomes based education (OBE) model, the graduates from the universities within a WA signatories countries, 
must be shown to achieve the expected outcomes of a graduating engineer or the so called "Graduate Attributes" outlined by the WA as (Washington Accord, 2009) "Graduate attributes form a set of individually assessable outcomes that are the components indicative of the graduate's potential to acquire competence to practise at the appropriate level. The graduate attributes are exemplars of the attributes expected of graduate from an accredited programme. Graduate attributes are clear, succinct statements of the expected capability, qualified if necessary by a range indication appropriate to the type of programme."

The Board of Engineers Malaysia (BEM) subsequently introduced a new accreditation manual based on the OBE approach (Engineering Accreditation Council, 2007). Since 2007, all the 4-year engineering degree programmes in Malaysia have been accredited under the OBE approach which put a very strong emphasis on the programme educational objectives (PEO) and programme outcomes (PO) assessment and evaluation. In this paper, we will present a general model for the PO assessment typically used by most of the engineering faculties in Malaysia. The model will be objectively analysed to pinpoint the weaknesses and areas for further improvement. Through this analysis, we hope to suggest an improved model that will be more effective and practical.

\section{Programme Outcomes Definition}

Under the EAC manual, programme outcomes (PO) is defined as statements that describe what students are expected to know and be able to perform or attain by the time of graduation. These relate to the skills, knowledge, and behaviour that students acquire through the programme (Engineering Accreditation Council, 2007). The outcomes expected of the Malaysian engineering graduates must include at least the following attributes:

1) ability to acquire and apply knowledge of science and engineering fundamentals;

2) acquiring in-depth technical competence in a specific engineering discipline;

3) ability to undertake problem identification, formulation and solution;

4) ability to utilise systems approach to design and evaluate operational performance;

5) understanding of the principles of sustainable design and development;

6) understanding of professional and ethical responsibilities and commitment to these;

7) ability to communicate effectively, not only with engineers but also with the community at large;

8 ) ability to function effectively as an individual and in a group with the capacity to be a leader or manager as well as an effective team member;

9) understanding of the social, cultural, global and environmental responsibilities of a professional engineer, and the need for sustainable development; and

10) recognising the need to undertake life-long learning, and possessing/acquiring the capacity to do so.

Because programmes have control of and direct access to their students up until graduation, outcomes are more conducive to data gathering and assessment and have therefore received more attention and a higher level of expectations in the accreditation process (Estes \& Ressler, 2007). Thus, the major challenge for most of the engineering programmes in Malaysia is to prove that their graduates are able to achieve the PO. The programme is expected to show that a process of measuring, assessing and evaluating the degree of achievement of the students shall be established. Subsequently, the results of this assessment process shall be applied for continual improvement of the programme.

\section{Model of PO Assessments in most Malaysian Universities}

A general model of PO assessment has been deduced based on the various self-accreditation reports of engineering programmes that had undergone the accreditation process in Malaysia. Due to confidentiality matter, the names of the parent universities will not be mentioned. The author himself was the lead panel assessor for each of the programme.

Figure 1 summarises the PO assessment model for all the programmes. In general the assessment model features the following:

1) For every course within the curriculum, the course outcomes are linked directly to the respective PO.

2) The $\mathrm{CO}$ will be assessed using direct method consisting of quizzes, tests and exams, lab report, project report etc. Some programmes use rubric for soft skillsassessment.

3) The final marks will be a composite sum of individual marks at a specified percentage and normalised to 100 percent. 
4) Based on the link between $\mathrm{CO}$ and PO, the achievement of each PO is determined based on the marks input. Then the achievement of the PO is obtained by averaging each of the mark for the PO.

5) A performance indicator is normally assumed to be about 60 percent.

6) Indirect methods consist of surveys - exit survey, end of course survey, and industrial training survey. The findings from this survey will be presented separately from the average mark.

The average marks for each PO will be presented in a plot such as that shown in Figure 2. Thus the programme will make a deduction that the PO has been achieved if the average mark for the PO is greater than the specified indicator (normally 60\%).

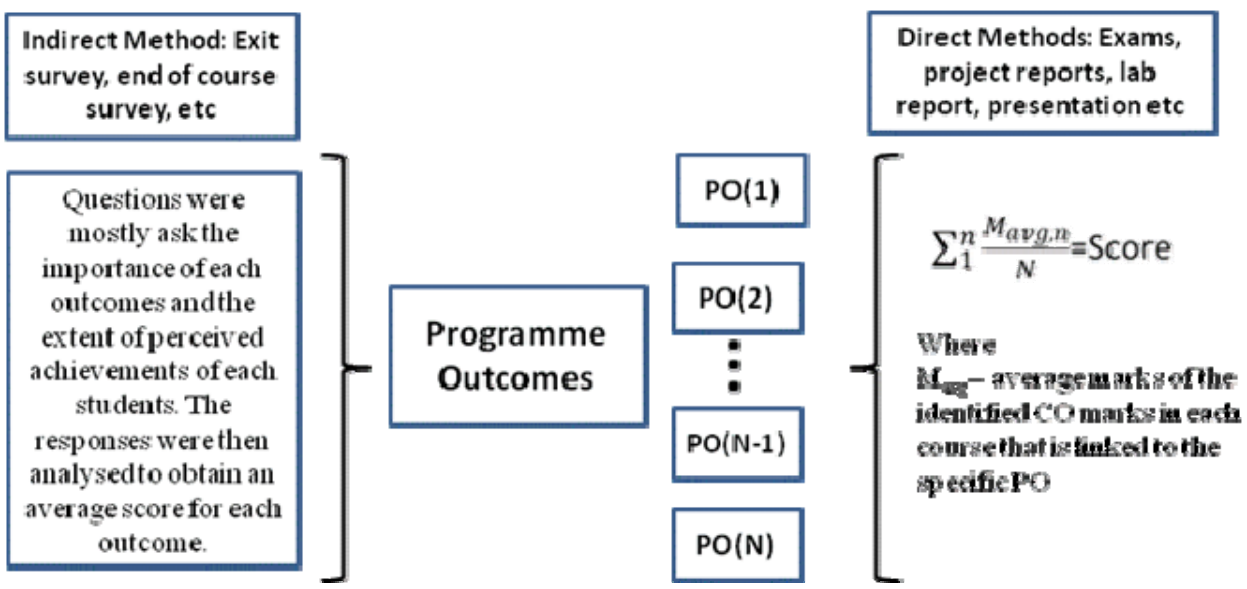

Figure 1. The typical model of PO assessment in Malaysian engineering programmes

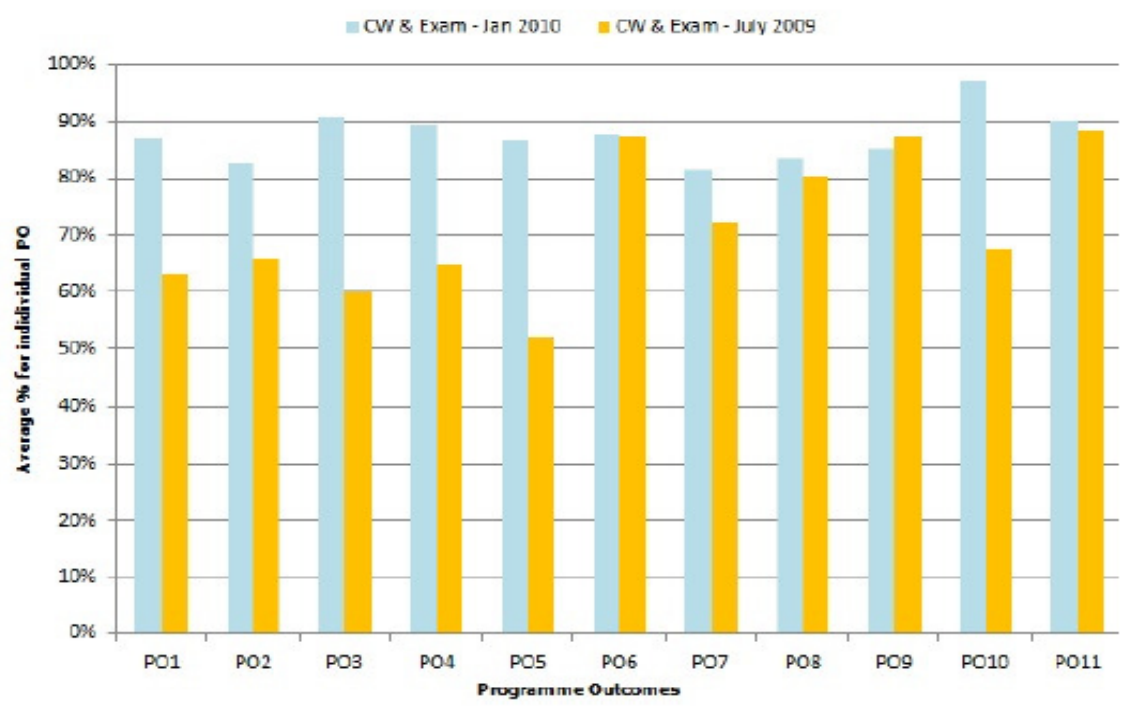

Figure 2. Examples on how PO assessment results are presented 


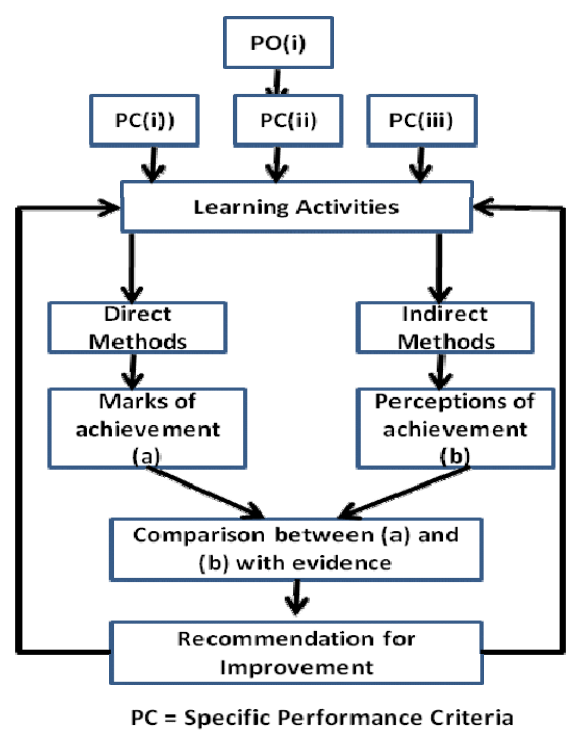

Figure 3. Proposed improved model for PO assessment

\section{Analysis of the Model}

Rogers (2006) has articulated very well that the focus of the data collection during the programme outcome assessment is to answer the question, "Can the program demonstrate the level to which students have attained the anticipated student outcomes?". The evidence of student learning is then used to identify student strengths and weaknesses related to each of the student outcomes for the purpose of making decisions about how to improve the program teaching/learning processes. This evidence should be the product of faculty reviewing and/or observing student work related to the program requirements. This concept leads to the whole purpose of the OBE approach which is to have a Continual Quality Improvement (CQI) within the programme.

In view of the model presented above, the link to CQI within the programme was certainly not obvious. Most programmes have failed to show how the data that have been collected can be used to further improve the quality of students graduating from the programme. Specifically the issues and weaknesses of the model above are within the following five aspects: (i) performance criteria, (ii) Grades as indicators, (iii) Evidence, (iv) Indirect Methods and (v) CQI.

The most glaring weakness of the model is the fact that no clear performance criteria were evidenced for each of the specific outcome. Performance criteria is defined as specific, measurable statements identifying the performance(s) required to meet the outcome; confirmable through evidence. For example, an outcome on "effective communication" for engineering students would require specific criteria covering (i) effective oral presentation, (ii) effective report writing, and possible (iii) mastery of language used in professional communication. These three specific criteria would require three types of measurement within the curriculum. Thus to lump sum one PO through a cumulative grade achieved in all courses will not allow a programme to know the extent of achievement and the gaps that exist for the specific outcome of "effective communication".

Secondly, the use of grades achieved in courses hid the specific achievement of the expected criteria. Rogers (2003) clearly explain the reasons why grades should not be used as indicators for outcome achievement. In a way, grades represent the extent to which a student has successfully met the faculty member's requirements and expectations for a course. Because many factors contribute to an assigned grade, it is almost impossible to make inferences about what a student knows or can do by only looking at the grades for a course. In outcomes assessment at the program level, the primary question that needs to be answered is, "Can students demonstrate the ability to perform at an acceptable level in each of the program outcomes?" Program assessment focuses on providing evidence that students can demonstrate knowledge or skill directly linked to specific program outcomes. Grades per se do not provide that information. Rogers (2003) pointly summarised that "It is important to remember that the focus is not a score or grade, but the student knowledge or skill that is represented by that score or grade".

Most programmes also failed to a certain extent to show the evidence of student achievements. Again, the dependence on grades per se has lulled the faculty members to assume that most students have met the outcomes. But further inspection of the course files showed there are many gaps still existed that have not even been 
identified properly by the programmes for further improvements.

The next issue is with regard to the use of indirect methods such as exit-survey, industrial training survey, and end-of-class survey to complement the assessment of outcomes. Indirect measures of student learning outcomes will provide additional information as to how the training or educational program is meeting curricular and learning objectives (McGlothin, 2009). Within the model of assessment above, indirect method data would have to be treated separately and not linked specifically to the targeted outcomes. There is no means of comparison between what are the perceptions of student's achievement and the achievement per se of specific level of competencies. Again this arose due to the failure to capture the performance criteria expected of the students.

All of the above issues have resulted in most programmes having problem to implement the continual quality improvement (CQI) required in the OBE approach. This is due to the fact that the use the use of the above model for outcome assessment shielded the program from knowing the real level of competencies that their students had achieved. Most will just say that their students have achieved the outcomes and thus no improvement is required.

\section{Proposed Improved Model}

In order to properly develop an effective assessment plan, the following principles outlined by American Association for Higher Education (Astin et al, 1991) must be upheld:

1) The assessment of student learning begins with educational values.

2) Assessment is most effective when it reflects an understanding of learning as multidimensional, integrated, and revealed in performance over time.

3) Assessment works best when the programs it seeks to improve have clear, explicitly stated purposes.

4) Assessment requires attention to outcomes but also and equally to the experiences that lead to those outcomes.

5) Assessment works best when it is ongoing, not episodic.

6) Assessment fosters wider improvement when representatives from across the educational community are involved.

7) Assessment makes a difference when it begins with issues of use and illuminates questions that people really care about.

8) Assessment is most likely to lead to improvement when it is part of a larger set of conditions that promote change.

9) Through assessment, educators meet responsibilities to students and to the public.

Based on the above principles, every programme must view the assessment model in a very holistic way as a mean to evaluate the student's achievement of the programme outcomes which will lead to improvement in student's knowledge, skills and attitude. A good assessment recognizes the value of information for the process of improvement (Deming, 2000; Wright, 1997). Thus each PO should be viewed as a major thrust with specific performance criteria which, upon measurement, will allow one to objectively evaluate whether the students have achieved the criteria. Figure 3 shows a conceptual basis for an improved program's assessment model. The differences between the typical model and the proposed model are briefly explained in Table 1 . The proposed model is expected to provide a clear framework for assessing each of the PO which will result in a more objective and strategic CQI implementation within the programme. However, more importantly it is hope that this will lead to marked improvement of the graduate's quality coming out of the engineering programmes in Malaysia. 
Table 1. Differences between the typical model and the proposed model

\begin{tabular}{lll}
\hline Aspects & \multicolumn{1}{c}{ Old Model } & \multicolumn{1}{c}{ Proposed Model } \\
\hline $\begin{array}{l}\text { Performance } \\
\text { criteria }\end{array}$ & $\begin{array}{l}\text { There are no clear and specific performance } \\
\text { criteria. The PO statement is assessed as it is. }\end{array}$ & $\begin{array}{l}\text { Each statement will have specific } \\
\text { performance criteria that will support the } \\
\text { measurement of each programme outcome. }\end{array}$ \\
\hline $\begin{array}{l}\text { Indicators of } \\
\text { achievement }\end{array}$ & $\begin{array}{l}\text { Average marks obtained in the final grades from } \\
\text { a range of courses or average of marks obtained } \\
\text { from a Likert scale in survey forms. The marks } \\
\text { will be averaged out and applicable specifically } \\
\text { for each programme outcome statement. }\end{array}$ & $\begin{array}{l}\text { Marks will be based on the specific } \\
\text { from cumulative of courses. Direct and } \\
\text { indirect methods will both have the same } \\
\text { basis of indicator to allow direct } \\
\text { comparison. }\end{array}$ \\
& $\begin{array}{l}\text { Since there is no clear performance criteria, } \\
\text { evidence will by itself unclear. }\end{array}$ & $\begin{array}{l}\text { Each performance criterion will be linked } \\
\text { to a specific evidence. Thus it is very easy } \\
\text { to show evidence of student's achievement. }\end{array}$ \\
\hline Evidences & $\begin{array}{l}\text { Improvement will not be easy to be made since } \\
\text { specific areas to be improved are unclear. }\end{array}$ & $\begin{array}{l}\text { Improvement can be clearly directed at the } \\
\text { criterion which fails to meet the } \\
\text { achievement. }\end{array}$ \\
\hline CQI & &
\end{tabular}

\section{Conclusions}

The engineering education in Malaysia underwent a major transformation starting in 2004 due to the requirement imposed by the Washington Accord agreement. Assessment and evaluation of programme outcomes (PO) are now mandatory for all engineering programmes in Malaysia. However, the typical PO assessment model practised by many engineering programmes resulted in vague assessment methods and as a result failed to show concrete continual quality improvement. The major issue have been the failure to have clear performance criteria for each of the outcome. A new model which is based on looking at each PO as a major thrust with specific performance criteria is proposed. It is expected that the new model will allow one to objectively evaluate whether the students have achieved the criteria and subsequently facilitate CQI implementation within the programme.

\section{Acknowledgements}

The authors would like to thank Universiti Kebangsaan Malaysia for providing the research grant OUP-2012-126 and PTS-2012-091 and appreciate the cooperative among the project partners. This work supported by the Centre for Engineering Education Research, Faculty of Engineering and Built Environment, Universiti Kebangsaan Malaysia, Bangi, Selangor, Malaysia.

\section{References}

Astin, A. W., Banta, T. W., Cross, K. P., El_Kawas, E. Ewell, P. T., Hutchings, P., \& Wright, B. D. (1991). 9 Principles of Good Practice for Assessing Student Learning. The American Association for Higher Education. Stylus Publishing, LLC.

Deming, W. E. (2000). Out of Crisis. Cambridge: MIT Press.

Engineering Accreditation Council, Engineering Programme Accreditation Manual. (2007). Borad of Engineers Malaysia.

Estes, A., \& Ressler, S. (2007). Surviving ABET Accreditations: Satisfying the Demands of Criterion 3. Proceedings of the 2007 ASEE Annual Conference \& Exposition, Honolulu, HI.

Killen, R. (2007). Teaching Strategies for Outcome Based Education (2nd ed.). Juta \& Co, Cape Town, South Africa.

McGlothin, C. W. (2009). Assessment of Student learning: direct and indirect methods at work. Journal of SH\&E Research, 6(1).

Rogers, G. (2003). Do Grades Make the Grade for Program Assessment? Assessment Tips with Gloria Rogers, Communications Link, the ABET News Source, ABET, Inc. Baltimore, Md. Fall/Winter, pp. 8-9.

Rogers, G. (2006). Direct and Indirect Assessments: What Are They Good For? Assessment 101, Assessment Tips with Gloria Rogers, Community Matters, A Monthly Newsletter for the ABET Community, ABET, Inc. 
Baltimore, Md. August, p. 3

Spady, W. (1994). Outcome-based education: Critical issues and answers. Arlington, VA: American Association of School Administrators.

Washington Accord. (2009). Retrieved from http://www.washingtonaccord.org/GradProfiles.cfm

Wright, B. D. (1997). Fundamental measurement for outcome evaluation. Physical medicine and rehabilitation: State of the Art Reviews, 11(2), 261-288.

Zitterkopf, R. (1994). A fundamentalist's defense of OBE. Educational Leadership, 51(6), 76-78. 